\title{
Remediation of Artificially Hydrocarbon Polluted Vadose Zone Soil in Glass Column through Percolation with Solution of Nutrient, Nutrient-Surfactant or Surfactant
}

\author{
1*PEEKATE, PL; ${ }^{2}$ KONNE, JL; ${ }^{3}$ ABAM, TKS \\ ${ }^{1}$ Department of Microbiology, Faculty of Science, Rivers State University, P. M. B. 5080 Port Harcourt, Nigeria \\ ${ }^{2}$ Department of Chemistry, Faculty of Science, Rivers State University, P. M. B. 5080 Port Harcourt, Nigeria \\ ${ }^{3}$ Institute of Geosciences and Space Technology, Faculty of Science, Rivers State University, P. M. B. 5080 Port Harcourt, Nigeria \\ *Corresponding Author Email: lekia.peekate@ust.edu.ng; Tel: +2348063353116
}

\begin{abstract}
Remediation of hydrocarbon polluted vadose zone (HPVZ) through percolation with solution of nutrient, nutrient-surfactant, or surfactant in glass columns was investigated in this study using standard methods. Percolated liquids from the columns and soils retrieved at the end of the experiment were analyzed for nitrate, phosphate, sulphate, total-petroleum hydrocarbon, and selected microbial groups. Results obtained showed that there were nitrate, phosphate, and sulphate in the percolated liquids. Cumulative hydrocarbon in the percolated liquids was $5.35-7.59 \%$ of cumulative hydrocarbon start-up concentration in the columns. Cumulative hydrocarbon attenuation across soil layers in column flooded with solution of nutrients (column NT), nutrient-surfactant (column NTS), and surfactant (column SF) were 89.29, 95.27, and $66.92 \%$ respectively. There was more phosphate reduction in column NTS, and more sulphate reduction in column NT. Hydrocarbon-utilizing fungi in columns NT and NTS increased from $3.5 \log _{10} \mathrm{CFU} . \mathrm{g}^{-1}$ to between $4.0-5.0 \log _{10} \mathrm{CFU} . \mathrm{g}^{-1}$, whereas a decrease was observed for column $\mathrm{SF}$. Hydrocarbon-utilizing bacteria in all the columns increased from between $1.0-2.5 \log _{10} \mathrm{CFU} . \mathrm{g}^{-1}$ to between 2.0 - $3.5 \log _{10}$ CFU.g ${ }^{-1}$. Emergence of hydrocarbon utilization among anaerobic bacteria population was also observed in all the columns. It is concludedthat percolation with nutrient-surfactant solution will be more effective in remediation of HPVZ, and that consequential migration of nutrients alongside hydrocarbons into groundwater can aid in enhancing biodegradation of the infiltrated hydrocarbons.
\end{abstract}

\section{DOI:https://dx.doi.org/10.4314/jasem.v24i6.9}

Copyright: Copyright (C) 2020 Peekate et al. This is an open access article distributed under the Creative Commons Attribution License (CCL), which permits unrestricted use, distribution, and reproduction in any medium, provided the original work is properly cited.

Dates: Received: 14October 2019; Revised: 16May 2020; Accepted: 10June 2020

Keywords: Biodegradation; petroleum hydrocarbons; vadose zone; inorganic nutrients; surfactant.

Apart from contamination of land surfaces resulting from crude oil spills, sub-surface vertical migration of the spill can occur.The migration can extend to soil layers (horizons) in the deep part of the vadose zone (Zhang et al., 2014). This may depend on the quantity of spilled hydrocarbons, frequency of rainfall, and nature of the soil layers making up the vadose zone. Contaminated soil layers in the deep part of the vadose zone are long-term source of groundwater pollution (Abdel-Moghny et al., 2012). Groundwater pollution will lead to unavailability of portable drinking water in communities that rely on such water resources, and in the long run result to decline in community health. There is thus a need to remediate contaminated vadose zones. Use of conventional soil surface based remediation strategies such as tilling or application of solid compendium of nutrients (Chorom et al. 2010; Ezeonu et al., 2012) is not feasible in remediating petroleum contaminated soil layers in deeper part of the vadose zone. Liquid formulations of nutrientsor surfactants, and water-based, surfactant-based, and foam-based oxidative formulations have been investigated for use in the remediation of simulated petroleum-hydrocarbon contaminated vadose zone through continuous flooding or forced flushing (Boopathy, 2004; Bouzid et al., 2019; Widrig and Manning, 1995; Tindall et al., 2005; Zhu et al., 2005). These investigations were however targeted at single fractions of petroleum, and one or two soil layers. Vadose zones can be made up of one or more soil layers depending on geological regions. In the Niger Delta area of Nigeria, the vadose zone is made up of two to seven soil layers (Tamunobereton-ari et al., 2018; UNEP, 2011). Liquid flow through different vadose zones made up of different number of soil layers will be different. The effectiveness of a formulation for remediation of contaminated vadose zones will thus be dependent on the nature of the vadose zone studied. There will also be differences in the effectiveness of a formulation or procedure in the degradation of single fractions of petroleum and whole petroleum. This has been observed in laboratory setups with degradation being more with single fractions than mixed petroleum fractions (Auffret et al., 2009). There will thus be differences in the effectiveness of a formulation for vadose zones that were polluted with

*Corresponding Author Email: lekia.peekate@ust.edu.ng; Tel: +2348063353116 
single fractions of petroleum and vadose zones that were polluted with whole petroleum. The objective of this study is to investigate the use of nutrient, nutrientsurfactant, or surfactant percolation in the remediation of artificially hydrocarbon polluted vadose zones soils in columns. The aim is to determine which of nutrient, nutrient-surfactant, or surfactant solution will be effective in the remediation of crude oil polluted vadose zones.

\section{MATERIALS AND METHODS}

Vadose zone soil sample collection: Soil samples were collected from surface to a depth where saturation occurred at a site $\left(4^{\circ} 54^{\prime} 32.7^{\prime \prime} \mathrm{N}, 7^{\circ} 02^{\prime} 41.9^{\prime \prime} \mathrm{E}\right)$ in the Niger Delta area of Nigeria. Surface soil sample collection was achieved with the aid of shovels to a depth of $40 \mathrm{~cm}$. Sample collection beyond this depth was made possible with the aid of borehole drilling equipment. Samples were collected and coded based on the soil layers making up the vadose zone, and the depth of each layer was noted. Soil samples of each layer were transferred separately into large sampling containers, and transported to the Microbiology Laboratory of the Rivers State University, Nigeria for vadose zone simulation studies.

Simulation of petroleum hydrocarbon contaminated vadose zone: Four cylindrical glass columns having a base shaped like a funnel with an opening was used to simulate the vadose zone environment. The columns were supported at the middle and at the base by metal ring support attached to a customized designed stand. Non-absorbent packing material was filled into the base, and then the columns were filled with soils from the sampled vadose zone. The soils were filled layer by layer, according to how they were found in the vadose zone. The thickness of each soil layer in the column was set relative to the ratio in which they occurred in the vadose zone so as to obtain a total vadose zone experimental thickness of $50 \mathrm{~cm}$. The filled columns were labelled SC (setup for determination of start-up concentrations), NT (setup for percolation with nutrient solution), NTS (setup for percolation with nutrient-surfactant solution), and SF (setup for percolation with surfactant solution). Each column was artificially contaminated with $150 \mathrm{ml}$ crude oil, and $500 \mathrm{ml}$ capacity Erlenmeyer flasks were placed beneath the base of the columns. The columns were left undisturbed overnight for drainage of excess oil.

Assessment of contamination and nutrient levels, and microbial population: The soils in column SC were evacuated and the concentration of total petroleum hydrocarbons (TPH), nitrate, phosphate, and sulphate of each soil layer were determined. TPH was determined using gas chromatography/mass spectrophotometry (GCMS) and visible spectrophotometry (VS). The soil layers were also analysed for populations of total heterotrophic bacteria (THB), anaerobic bacteria (ANB), hydrocarbonutilizing bacteria (HUB), hydrocarbon-utilizing anaerobic bacteria (HUA), total fungi (TF) and hydrocarbon utilizing fungi (HUF). TF and HUF populations were determined for only the top soil layer.

Experimental operation and analysis: Column NT, NTS and SF were flooded with $300 \mathrm{ml}$ solution of nutrients, nutrient-surfactant, and surfactant respectively (Table 1) on day $0,7,14,21$, and 28 . Percolated liquids from the columns were analysed for concentrations of nitrate, phosphate, sulphate, and TPH. At the end of the experimental period (day 28), after collection of percolated liquids, the columns were evacuated and soils from the soil layers were analyzed for concentrations of nitrate, phosphate, sulphate, and TPH. The soils were also analyzed for populations of THB, HUB, ANB, HUA, TF and HUF.

Table 1: Composition of $1 \mathrm{~L}$ of the nutrient, nutrient-surfactant,

\begin{tabular}{llll}
\multicolumn{4}{c}{ and surfactant solutions } \\
\hline Components & NT & NTS & SF \\
\hline $\mathrm{MgSO}_{4} .7 \mathrm{H}_{2} \mathrm{O}$ & $0.4 \mathrm{~g}$ & $0.4 \mathrm{~g}$ & - \\
$\mathrm{KH}_{2} \mathrm{PO}_{4}$ & $0.8 \mathrm{~g}$ & $0.8 \mathrm{~g}$ & - \\
$\mathrm{Na}_{2} \mathrm{HPO}_{4}$ & $1.3 \mathrm{~g}$ & $1.3 \mathrm{~g}$ & - \\
$\mathrm{NaNO}_{3}$ & $0.4 \mathrm{~g}$ & $0.4 \mathrm{~g}$ & - \\
$\mathrm{Tap}$ water & $1,000 \mathrm{ml}$ & $900 \mathrm{ml}$ & $900 \mathrm{ml}$ \\
$\mathrm{SF}(0.05 \% \mathrm{w} / \mathrm{v})$ & - & $100 \mathrm{ml}$ & $100 \mathrm{ml}$ \\
\hline
\end{tabular}

SF $(0.05 \% \mathrm{w} / \mathrm{v}):$ solution of $0.5 \mathrm{~g}$ detergent containing alkylbenzenesulfonates, an anionic surfactant, in 1 L tap water),

NT: nutrient solution, NTS: nutrient-surfactant solution.

Determination of nutrient levels: Nutrient levels in the soils and percolated liquids were determined in the form of nitrate, phosphate, and sulphate concentrations. Nitrate concentration was determined using Brucine method (EPA, 1971); sulphate concentration was determined using turbidimetric method (APHA method 4500-SO42; APHA, 1992), while phosphate concentration was determined using ascorbic acid method (APHA method 4500-P; APHA, 1992).

Determination of TPH concentration: TPH in the percolated liquids and soils were determined through VS. A 721 VIS Spectrophotometer (Huanghua Faithful Instrument Co. Ltd, China) set at $420 \mathrm{~nm}$ was used to measure the absorbance of petroleumhydrocarbon extracts obtained from the samples with the aid of hexane. The absorbance values were then used to calculate TPH concentrations with the aid of the equation of the standard plot of absorbance versus crude oil concentration. 
Determination of population of TF and HUF: TF population was determined using Sabouraud dextrose agar and spread plate technique. Inoculated plates were incubated at ambient temperatures $\left(29-31{ }^{\circ} \mathrm{C}\right)$ for 3-5 days. HUF population was determined using modified mineral salts agar medium of Odokuma and Dickson (2003) supplemented with streptomycin and tetracycline, $50 \mu \mathrm{g} \cdot \mathrm{ml}^{-1}$ each. Inoculation was done using spread plate technique, and petroleum hydrocarbons were supplied into inoculated plates through the vapour phase transfer technique (Ebuehi et al., 2005). The plates were incubated at ambient conditions for 5-7 days.

Determination of the populations of THB, $H U B, A N B$, and HUA: THB population was determined using nutrient agar and spread plate technique. Inoculated plates were incubated at $37{ }^{\circ} \mathrm{C}$ for $24 \mathrm{~h}$. For determination of ANB population, nutrient agar and pour plate technique was used, and inoculated plates were incubated in anaerobic gas jars at ambient temperatures for 3 days. HUB population was determined using modified mineral salts agar medium of Odokuma and Dickson (2003) supplemented with 1 $\mathrm{mg} \cdot \mathrm{ml}^{-1}$ Nystatin. Inoculation was done through spread plate technique, and petroleum hydrocarbons were supplied into inoculated plates through vapour phase transfer technique. The plates were incubated at ambient conditions for 7 days. HUA population was also determined using the method for HUB population, but pour plate method was used in place of spread plate technique, and incubation was done in anaerobic gas jars.

Assessment of hydrocarbon attenuation: The extent of hydrocarbon attenuation in each soil layer of the soil columns was determined by calculating the proportion of hydrocarbon lost based on the TPH concentrations remaining at the end of the experiment in relation to the initial TPH concentrations. The time it will take for hydrocarbon concentrations in the different soil layers in the columns to reduce to $1 \mathrm{mg} \cdot \mathrm{Kg}^{-1}$ through biodegradation was calculated using the equation of a first order reaction, $\log [\mathrm{A}]_{\mathrm{t}}=(-K t / 2.303)+\log$ $[\mathrm{A}]_{0}$ (Manilla et al., 2001).

\section{RESULTS AND DISCUSSION}

Number and thickness of soil layers in the simulated vadose zone: During soil collection from the sampled vadose zone, the zone was observed to be made up of six different soil layers to a depth of $12 \mathrm{~m}$ where saturation occurred; saturation occurred about $0.6 \mathrm{~m}$ deep into the $6^{\text {th }}$ soil layer. Vadose zones in the Niger Delta area of Nigeria, has been shown to be made up of two to seven soil layers (Tamunobereton-ari et al., 2018; UNEP, 2011). The observation of six soil layers in the vadose zone sampled is thus within the range of the number of soil layers that can be found in the vadose zone of an area within the Niger Delta area of Nigeria.The different soil layers in the sampled vadose zone were coded $\mathrm{A}-\mathrm{F}$, in a sequential top to bottom manner. The approximate thickness of each of the soil layers are as follows: A $-0.4 \mathrm{~m}, \mathrm{~B}-2.6 \mathrm{~m}, \mathrm{C}-5.4 \mathrm{~m}$, $\mathrm{D}-2.1 \mathrm{~m}, \mathrm{E}-0.9 \mathrm{~m}$, and $\mathrm{F}>0.6 \mathrm{~m}$. Based on the total depth of the soil layers making up the vadose zone, the glass columns were filled from bottom to top so as to obtain the chosen vadose zone experimental thickness of $50 \mathrm{~cm}$ as follows: $\mathrm{F}-2.5 \mathrm{~cm}$ thickness, $\mathrm{E}-3.8 \mathrm{~cm}$ thickness, $\mathrm{D}-8.8 \mathrm{~cm}$ thickness, $\mathrm{C}-22.5 \mathrm{~cm}$ thickness, $\mathrm{B}-10.8 \mathrm{~cm}$ thickness, $\mathrm{A}-1.7 \mathrm{~cm}$ thickness; leading to a total of $50.1 \mathrm{~cm}$ in thickness.

Contamination and nutrient levels in simulated vadose zone: Following artificial contamination with crude oil, and draining of excess oil, the amount of crude oil (TPH) adsorbed in the various soil layers of the SC column as determined through GCMS and VS is shown in Table 2. From the Table it can be seen that TPH concentrations obtained through VS $(5,407-$ $\left.56,533 \mathrm{mg} \cdot \mathrm{Kg}^{-1}\right)$ is higher than that obtained through GCMS $\left(1,800 \quad-19,935 \quad \mathrm{mg} \cdot \mathrm{Kg}^{-1}\right)$. This is understandably so being that different methods for determination of TPH have been shown to have different performance score (Okparanma and Mouazen, 2013); fluorescence spectroscopic technique having the best performance score $(85 \%)$ and gravimetric technique having the least performance score $(60 \%)$. However, a review by Adeniji et al., (2017) showed that each method has its own advantages and disadvantages, and that the choice of a method should be guided by the type of data needed. In this research, the data needed was for monitoring reduction in TPH concentration. The VS method which is far less expensive than the GC-MS method was thus adopted for subsequent analysis. Though TPH concentrations obtained through VS was higher than that obtained through GCMS, both methods showed TPH reduction from soil layer A to E, and TPH increase from soil layer E to $F$. This pattern of decrease and increase has been observed in a similar study carried out by Kristensen et al. (2010). In the study, a decrease in TPH concentration was observed as one goes down from the sandy-limely loam-gravel layer to the sandy-limely loam layer, followed by an increase from the fine sand layer to the coarse sand layer, and then a decrease to the silt loam layer. Nutrient levels in the various soil layers in the form of concentrations of phosphate, nitrate, and sulphate are also shown in Table 2. From the Table it can be seen that there was presence of nitrate and phosphate in the soils, ranging from $0-$ 1,092 mg. $\mathrm{Kg}^{-1}$ and $0-73.92 \mathrm{mg} \cdot \mathrm{Kg}^{-1}$ respectively, but 
little or no sulphate. Also there was a general decrease in the concentration of nitrate and phosphate from the top to the bottom soil profile. A similar scenario has been observed by Jobbagy and Jackson (2001), and Tuovinen et al. (2015); phosphorus concentrations in soils were noticed by Jobbagy and Jackson (2001) to be far greater than sulphate, and phosphorus was also more concentrated in top soils than bottom soil profiles. Tuovinen et al. (2015) observed that total nitrogen content decreased with increase in soil depth.

Table 2: Contaminant and nutrient levels in simulated vadose zone

\begin{tabular}{|c|c|c|c|c|c|}
\hline \multirow[t]{2}{*}{ SLC } & \multicolumn{2}{|c|}{ TPH (mg. $\left.\mathrm{Kg}^{-1}\right)$} & \multirow{2}{*}{$\begin{array}{l}\text { Nitrate } \\
\left(\mathrm{mg.Kg}^{-1}\right)\end{array}$} & \multirow{2}{*}{$\begin{array}{l}\text { Phosphate } \\
\left(\mathrm{mg.Kg}^{-1}\right)\end{array}$} & \multirow{2}{*}{$\begin{array}{l}\text { Sulphate } \\
\text { (mg.Kg }\end{array}$} \\
\hline & GCMS & VS & & & \\
\hline $\mathrm{A}$ & 19,935 & 56,533 & 579 & 73.92 & $\leq 0.67$ \\
\hline B & 11,162 & 31,733 & 423 & 7.44 & $\leq 0.67$ \\
\hline $\mathrm{C}$ & 8,526 & 14,413 & 67 & 54.14 & $\leq 0.67$ \\
\hline $\mathrm{D}$ & 4,925 & 7,793 & 1,092 & 27.78 & $\leq 0.67$ \\
\hline $\mathrm{E}$ & 1,800 & 5,407 & $\leq 2.23$ & 19.96 & $\leq 0.67$ \\
\hline $\mathrm{F}$ & 6,502 & 9,067 & 134 & $\leq 0.01$ & $\leq 0.67$ \\
\hline $\mathrm{TT}$ & 52,850 & 124,946 & - & - & - \\
\hline
\end{tabular}

SLC: soil layer code, GCMS: Gas chromatography and mass spectrophotometry, VS: visible spectrophotometry, TT: total.

Table 3: Population of selected microbial groups in soil layers of simulated contaminated vadose zone

\begin{tabular}{ccccccc}
\hline SL & \multicolumn{6}{c}{ Microbial population (CFU.g $\mathbf{g}^{-1}$ ) } \\
& TF & HUF & THB & HUB & ANB & HUA \\
\hline A & $1.30 \times 10^{4}$ & $4.00 \times 10^{3}$ & $4.7 \times 10^{7}$ & $1.35 \times 10^{2}$ & $1.28 \times 10^{5}$ & 0 \\
B & - & - & $1.0 \times 10^{5}$ & $1.45 \times 10^{2}$ & $2.02 \times 10^{6}$ & 0 \\
C & - & - & $5.0 \times 10^{5}$ & $1.00 \times 10$ & $3.00 \times 10^{4}$ & 0 \\
D & - & - & $1.0 \times 10^{6}$ & $1.33 \times 10$ & $6.72 \times 10^{4}$ & 0 \\
E & - & - & $6.0 \times 10^{5}$ & $1.12 \times 10$ & $9.10 \times 10^{4}$ & 0 \\
F & - & - & $3.0 \times 10^{5}$ & $3.00 \times 10$ & $2.00 \times 10^{3}$ & 0
\end{tabular}

SL: soil layer, TF: total fungi, HUF: hydrocarbon utilizing fungi, THB: Total heterotrophic bacteria, HUB: hydrocarbon utilizing bacteria, ANB: anaerobic bacteria population, HUA: hydrocarbon utilizing anaerobic bacteria.

Microbial population in simulated vadose zone: Population of selected microbial groups in each soil layers of the simulated contaminated vadose zone are presented in Table 3. From the Table, it can be seen that there was no hydrocarbon utilizing anaerobic bacteria in all the soil layers, and that the population of the other group of bacteria generally reduced from the top soil layer to the bottom soil layer. In related studies, soil microbial population have been shown to decrease with increasing soil depth (Bhattaria et al., 2015; Stocker et al., 2015). The variation of bacterial population with soil depth as observed in this study is thus in agreement with available facts.

Presence of hydrocarbon in percolated liquids: TPH concentration in percolated liquids from the soil columns is presented in Fig. 1. From the Figure it can be seen that the percolated liquids had hydrocarbons in them which reduced from between 4,000 - 4,500 mg.L $\mathrm{L}^{-1}$ to between $100-500 \mathrm{mg} . \mathrm{L}^{-1}$. The cumulative amount of hydrocarbons in percolated liquids from the three soil columns from day $0-28$ ranged from 6,680 - 9,484 mg. $\mathrm{L}^{-1}$, whereas the cumulative start-up concentration of petroleum hydrocarbons across the soil layers in the columns was 124,946 mg. Kg-1 (Table 2 ). Relating these values shows that the cumulative hydrocarbon concentration in the percolated liquids is $5.35-7.59 \%$ of the cumulative hydrocarbon start-up concentration in the simulated vadose zone. This implies that $5.35-7.59 \%$ of hydrocarbons in a contaminated vadose zone having six soil layers will migrate due to percolation with nutrient and/or surfactant solution into underlying groundwater. In reality, the range may be lower taking into cognizance actual thickness and compaction of the different soil layers. Generally, hydrocarbon reduction in percolated liquid from column NTS was more than in the other columns (Fig. 1). This can be attributed to desorption of hydrocarbons from soil particles as a result of surfactant action followed by enhanced biodegradation as a result of provision of nutrients for optimal stimulation of inherent hydrocarbon-utilizing microorganisms. Nutrient-surfactant mix has been shown to enhance desorption and solubilisation of entrapped hydrocarbons for subsequent enhanced biodegradation (Zoller and Reznik, 2006). In another related study, surfactant in combination with a nutrient resulted in TPH reduction of $52-72 \%$, whereas only the nutrient resulted in $34-66 \%$ reduction (Asquith et al., 2012). Surfactants only enhances desorption and solubilisation of hydrocarbons (Zhu and Aitken, 2010). This fact is observable in Fig. 1 where percolated liquid from column ST had the highest TPH for most part of the study period.

Presence of nutrients in percolated liquids: Nutrient concentrations in the form of phosphate, nitrate, and sulphate in percolated liquids from the columns are presented in Fig. 2 - 4. 


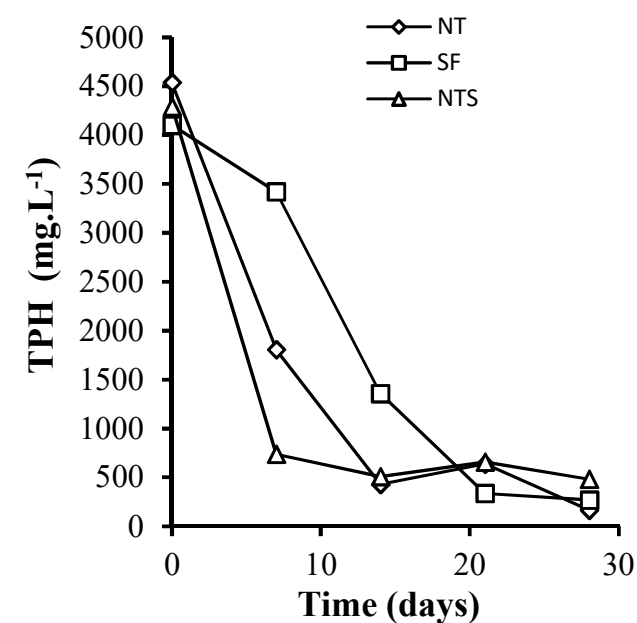

Fig. 1: Total petroleum hydrocarbon (TPH) concentration in percolated liquids

NT: soil column flooded with nutrient solution, SF: soil column flooded with surfactant solution, NTS: soil column flooded with nutrient-surfactant solution.

In Fig. 2, it can be seen that there was presence of phosphate in percolated liquids from columns NT and NTS, but little or none for column SF. In Fig. 3, it can be seen that there was presence of nitrate in percolated liquids from all the columns; and it was more for columns NT and NTS than for column SF. In Fig. 4, it can be seen that for percolated liquid from column NTS there was a general increase in the amount of sulphate, for column NT there was an increase followed by a decrease, and there was no sulphate in percolated liquid from column SF. Nutrients were not provided in the solution supplied to column SF, thus the predominant absence of phosphate and sulphate.

The presence of nitrate in percolated liquid from column SF could be attributed to leaching of nitrates present in the soil layers. From the information in Fig. $2-4$, it can be deduced that some quantity of supplied nutrients in solutions percolating through a hydrocarbon contaminated vadose zone will migrate to underling groundwater. Infiltration of sulphate has been shown to enhance biodegradation of petroleum hydrocarbons in shallow impacted groundwater systems (Wei et al., 2018). Also, nitrate addition has been shown to enhance biodegradation of selected hydrocarbons in laboratory scale flow-through aquifer columns (Anid et al, 1993). Thus migration of supplied nutrients into underlying groundwater can result in enhancing biodegradation potential of bacteria present in groundwater so as to achieve biodegradation of infiltrated hydrocarbons.

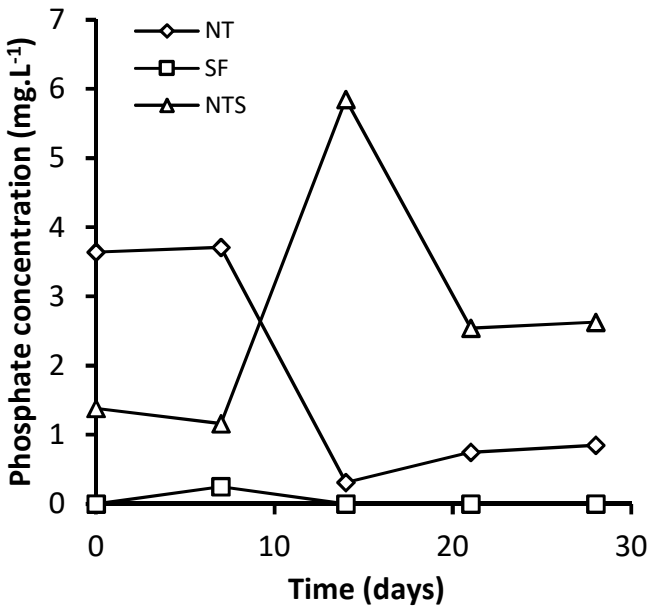

Fig. 2: Phosphate concentration in percolated liquids. $N T$ : soil column flooded with nutrient solution, SF: soil column flooded with surfactant solution, NTS: soil column flooded with nutrient-surfactant solution.

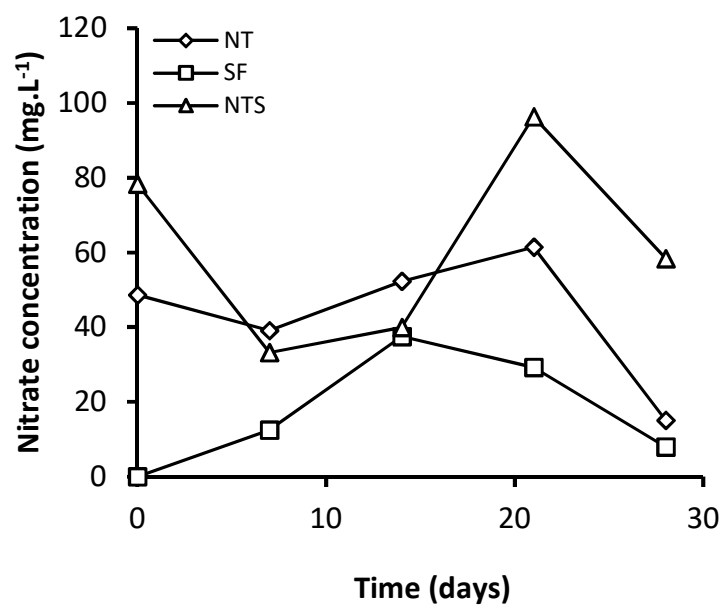

Fig. 3: Nitrate concentration in percolated liquids.

Hydrocarbon attenuation in simulated vadose zone: TPH concentration in each soil layer of the columns at the end of the experiment, and the extent of hydrocarbon attenuation are presented in Table 4 . From the Table, it can be seen that the attenuation percentage of the cumulative hydrocarbon concentration across the soil layers in columns NT, NTS, and SF are 89.29, 95.27, and 66.92\% respectively. This shows that hydrocarbon attenuation was highest in column NTS. Therefore, nutrientsurfactant solution will be more effective than the other solutions in the remediation of petroleum hydrocarbon contaminated vadose zone. Superiority of the use of nutrients in combination with surfactants than surfactants alone in the biodegradation of hydrocarbons has been observed in other related 
research works (Calvo et al., 2008; Zhang et al., 1998; Zoller and Reznik 2006).

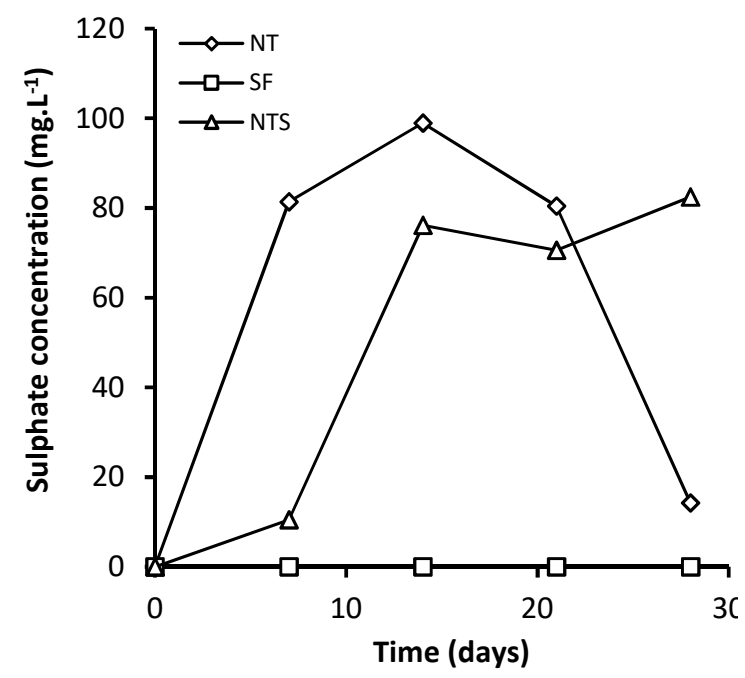

Fig. 4: Sulphate concentration in percolated liquids.
Studies comparing chemically synthesized surfactants and nutrient mixture versus nutrients in the biodegradation of hydrocarbons are not globally available as of the time of this study. However, such studies exist for nutrient-biosurfactant mixture versus only nutrients. Brown et al. (2017) showed that a combination of nutrients, biochar and biosurfactant removed $23 \%$ more TPH than nutrient alone. Cameotra and Singh (2008) obtained more than $98 \%$ hydrocarbon depletion when a nutrient mixture and a crude biosurfactant preparation were used together; separate use of the nutrient mixture or the biosurfactant resulted in 91 - $95 \%$ hydrocarbon depletion in 4 weeks. Thavasi et al. (2011) showed that crude oil degradation of about $3.2-7 \%$ higher is achievable with fertilizer-biosurfactant mixture than with only biosurfactant or fertilizer. The achievement of higher hydrocarbon attenuation percentage with the use of nutrient-surfactant solution in this study is thus in agreement with what has been observed in related research works.

\begin{tabular}{|c|c|c|c|c|c|c|c|}
\hline \multirow[t]{2}{*}{ SL } & \multirow{2}{*}{ 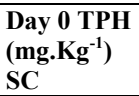 } & \multicolumn{3}{|c|}{ Day 28 TPH (mg.Kg $\left.{ }^{-1}\right)$} & \multicolumn{3}{|c|}{ EHA $(\%)$} \\
\hline & & NT & NTS & SF & NT & NTS & SF \\
\hline $\mathrm{A}$ & 56,533 & 4,133 & 1,500 & 23,400 & 92.69 & 97.35 & 58.61 \\
\hline B & 31,733 & 1,913 & 690 & 9,280 & 93.97 & 97.83 & 70.76 \\
\hline $\mathrm{C}$ & 14,413 & 647 & 800 & 2,580 & 95.51 & 94.45 & 82.10 \\
\hline $\mathrm{D}$ & 7,793 & 73 & 54 & 433 & 99.06 & 99.31 & 94.44 \\
\hline E & 5,407 & 2,120 & 920 & 1,730 & 60.79 & 82.99 & 68.00 \\
\hline F & 9,067 & 4,500 & 1,947 & 3,913 & 50.37 & 78.53 & 56.84 \\
\hline TT & 124,946 & 13,39 & 5,911 & 41,336 & 89.29 & 95.27 & 66.92 \\
\hline
\end{tabular}

SL: soil layer, SC: Start-up concentration, NT: soil column flooded with nutrient solution, NTS: soil column flooded with nutrient-surfactant solution, SF: soil column flooded with surfactant solution, EHA: extent of hydrocarbon attenuation [(initial TPH - final TPH) $\times 100 \% /$ initial TPH]. TT: total.

Attenuation of petroleum hydrocarbons in terms of biodegradation has been shown to follow a first order reaction (Hohener et al., 2003; Yudono et al., 2011).

Table 5: Calculated degradation constant and time for reduction of TPH to $1 \mathrm{mg} . \mathrm{Kg}^{-1}$

\begin{tabular}{|c|c|c|c|c|c|c|}
\hline \multirow[b]{2}{*}{ SL } & \multicolumn{3}{|c|}{$K\left(\right.$ day $\left.^{-1}\right)$} & \multicolumn{3}{|c|}{$t_{c}$ (days) } \\
\hline & NT & NTS & SF & NT & NTS & SF \\
\hline A & 0.09 & 0.13 & 0.03 & 121.6 & 84.2 & 364.8 \\
\hline B & 0.10 & 0.14 & 0.04 & 103.7 & 74.0 & 259.2 \\
\hline $\mathrm{C}$ & 0.11 & 0.10 & 0.06 & 87.1 & 95.8 & 159.6 \\
\hline D & 0.17 & 0.18 & 0.10 & 52.7 & 49.8 & 89.6 \\
\hline $\mathrm{E}$ & 0.03 & 0.06 & 0.04 & 286.6 & 143.3 & 214.9 \\
\hline $\mathrm{F}$ & 0.03 & 0.05 & 0.03 & 303.8 & 182.3 & 303.8 \\
\hline
\end{tabular}

SL: soil layer, NT: soil column flooded with nutrient solution, NTS: soil column flooded with nutrient-surfactant solution, SF: soil column flooded with surfactant solution, $K$ : Degradation constant as calculated using first order reaction, $t_{c}$ : Calculated time for TPH to reduce to $1 \mathrm{mg} . \mathrm{Kg}^{-1}$.

The time it will take for hydrocarbon concentration in the different soil layers in the columns to reduce to 1 mg. $\mathrm{Kg}^{-1}$ through biodegradation as determined using the equation of a first order reaction is presented in Table 5. From Table 5 it can be seen that the time it will take for hydrocarbon concentration in the different soil layers to biodegrade to a concentration of 1 mg. $\mathrm{Kg}^{-1}$ (i.e. when $\log [\mathrm{A}]_{\mathrm{t}}=0$ ) in column NT ranges from about 53 - 304 days, about 50 - 182 days for column NTS, and about $90-365$ days for column SF. These ranges indicate that biodegradation of hydrocarbons in contaminated vadose zone will be achieved more rapidly through percolation with nutrient-surfactant solution than with the other solutions.

Nutrient utilization in simulated vadose zone: Phosphate, nitrate, and sulphate concentrations in each soil layer of the columns at the beginning and end of the experimental period are presented in Fig. 5 - 7. In Fig. 5, it can be seen that there was phosphate 
reduction in soil layers $\mathrm{A}, \mathrm{C}, \mathrm{D}$ and $\mathrm{E}$ for all the soil columns. The reduction was more in soil layers $\mathrm{A}$ and D for column NTS, more in soil layer C for column NT, and more in soil layer E for both NT and NTS. In soil layer $\mathrm{B}$, reduction in phosphate occurred only in column SF.

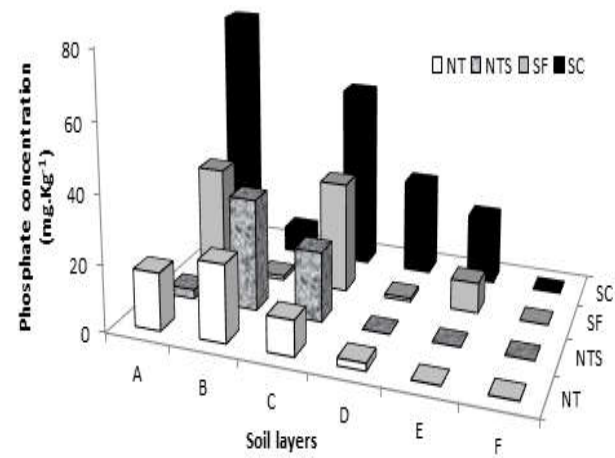

Fig. 5: Phosphate concentration in the soil layers at beginning and end of experiment.

SC: Start-up concentration, SF: soil column flooded with surfactant solution, NTS: soil column flooded with nutrientsurfactant solution, NT: soil column flooded with nutrient solution.

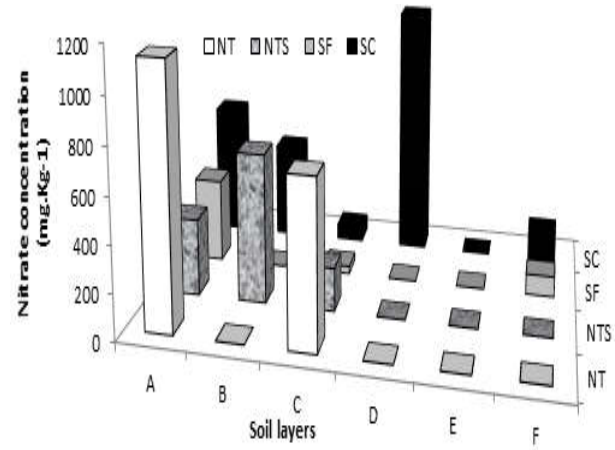

Fig. 6: Nitrate concentration in the soil layers at beginning and end of experiment.

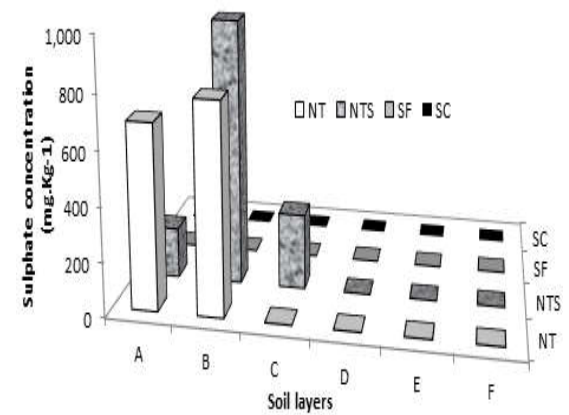

Fig. 7: Sulphate concentration in the soil layers at beginning and end of experiment.

These observations indicate that there was more phosphate reduction in column NTS. In Fig. 6, it can be seen that there was nitrate reduction in soil layer $\mathrm{D}$ and $\mathrm{F}$ for all the columns. In soil layer $\mathrm{A}$ there was nitrate reduction for columns NTS and SF. In soil layer $\mathrm{B}$ there was complete nitrate reduction for NT and SF. In soil layer $\mathrm{C}$ there was nitrate reduction for $\mathrm{SF}$. These observations indicate that nitrate reduction was generally the same for all the experimental soil columns. In Fig. 7, it can be seen that there was sulphate accumulation in soil layers $\mathrm{A}$ and $\mathrm{B}$ for columns NT and NTS, with the accumulation being higher in soil layer A for NT and higher in soil layer B for NTS. In soil layer $C$, sulphate accumulation occurred only for NTS. These observations indicate that sulphate supplied in solutions to NT and NTS was utilized more in soil layer A for NTS, and more in soil layers B and C for NT. It can thus be generally agreed that sulphate utilization was more for column NT. There was no sulphate in the solution supplied to column SF, so it can be assumed that sulphate was not utilized in any soil layers of SF. The reduction in phosphate, nitrate, and sulphate can be attributed to uptake and utilization by indigenous microorganisms for subsequent biodegradation of the hydrocarbon contaminant. Microbial uptake of nutrients such as phosphate and nitrogen has been shown to be necessary for biodegradation of hydrocarbons (Semboung-Lang et al., 2016; Sierra-Garcia and Oliveira, 2013).Since there was more phosphate reduction in soil column NTS than in NT, it can be implied that surfactant enhances microbial uptake of phosphate during biodegradation of petroleum hydrocarbons. Nitrate uptake by bacteria has been shown to be coupled with hydrocarbon metabolism under aerobic and anaerobic conditions (Kwapisz et al., 2008; Zedelius et al., 2011). Sulphate reduction which is generally agreed to be attributed to the activity sulphate reducing bacteria has been shown to be associated with anaerobic biodegradation of hydrocarbons (Sierra-Garcia and Oliveira, 2013; Wei et al., 2018). This could explain the relative accumulation of sulphate in the top soil layers (A and B); these layers are not predominantly anaerobic. On the other hand, since there was more sulphate utilization in column NT than NTS, it can be implied that surfactant interferes with sulphate reduction by microorganisms. In a related study, microbial surfactants have been shown to reduce biomass of sulphate reducing bacteria (Fenibo et al., 2019). Being that sulphate reducing bacteria (SRB) are the main group of microorganisms involved in sulphate reduction, it can be implied that SRB were present in the soils in NT and NTS, and that the SRB in NTS were negatively affected by the surfactant in the solution supplied to it, thus the relatively less sulphate utilization in it. 
Growth response of investigated microbial groups in simulated vadose zone: Fungi and bacteria populations in the soil layers of the columns at the beginning and end of the experimental period are presented in Fig. 8 12.

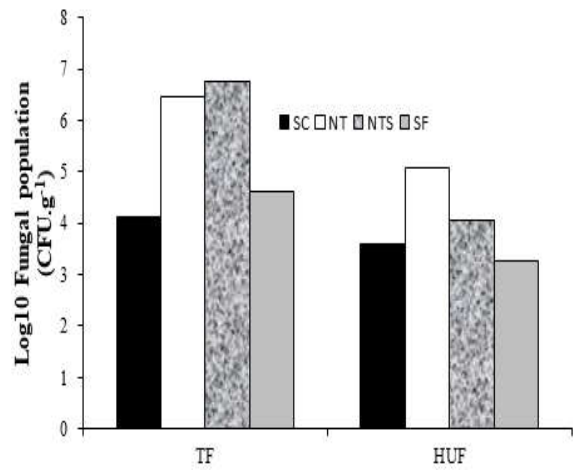

Fig.8: Population of total fungi (TF) and hydrocarbon utilizing fungi (HUF) in soil layer $\mathrm{A}$ at the beginning and end of the experiment.

In Fig. 8, it can be seen that there was increased from about $4.0 \log _{10}$ CFU.g ${ }^{-1}$ to between 4.5 - 7.0 $\log _{10}$ CFU.g ${ }^{-1}$ in total fungi population for all the soil columns, with the increase being more for column NTS and less for column SF. With regards to hydrocarbon utilizing fungal population, it can be seen that there was increased from about $3.5 \log _{10}$ CFU.g ${ }^{-1}$ to between $4.0-5.0 \log _{10} \mathrm{CFU} \mathrm{g}^{-1}$ for columns NT and NTS, with the increase being more for NT, and a slight decrease from about 3.5 to $3.0 \log _{10} \mathrm{CFU}_{\mathrm{g}} \mathrm{g}^{-1}$ for column SF. These observations shows that fungi will thrive better in petroleum hydrocarbon contaminated soils saturated with nutrient-surfactant solution than in contaminated soils saturated with surfactant solution, and also indicate that the presence of surfactant puts a slight pressure on hydrocarbon degrading ability of fungi. Selected surfactants have been shown by Chen et al., (2006) to restrain the degradation of polycyclic aromatic hydrocarbons by white-rot fungi. In other related studies, surfactants have been shown to inhibit spore germination and ergosterol production by fungi (Kozirog et al., 2018; Mwamburi et al., 2015; Tanuja et al., 2010). It can thus be generalized that surfactants puts a pressure on the hydrocarbon degrading ability of fungi, and this pressure can be relaxed in the presence of nutrients as observed in this study. In Fig. 9 , it can be seen that there was reduction from between 5.0 - 8.0 $\log _{10}$ CFU.g ${ }^{-1}$ to between 3.0 - $6.0 \log _{10}$ CFU.g ${ }^{-1}$ in the population of total heterotrophic bacteria (THB) across the soil layers in the three columns, except for soil layers $\mathrm{B}$ and $\mathrm{C}$ where the change in population was negligible. On the other hand, there was a general increase from between $1.0-$ $2.5 \log _{10}$ CFU.g ${ }^{-1}$ to between 2.0 - 3.5 $\log _{10}$ CFU.g ${ }^{-1}$ in the population of hydrocarbon utilizing bacteria (HUB) across the soil layers in the three columns (Fig. 10). In Fig. 11, it can be seen that there was decrease from between $5.0-6.5 \log _{10} \mathrm{CFU} . \mathrm{g}^{-1}$ to between 2.0 - $5.0 \log _{10} \mathrm{CFU} . \mathrm{g}^{-1}$ in the population of anaerobic bacteria (ANB) in soil layers A, B, and $\mathrm{E}$ for the three experimental columns. However, hydrocarbon utilizing ability in the anaerobic bacteria population was instigated by the different solutions as indicated in Fig. 12 by the emergence of hydrocarbon utilizing anaerobic bacteria (HUA) in soil layer A for columns SF and NTS, in soil layers B and C for the three columns, in soil layer D for NT and NTS, and in soil layers $\mathrm{E}$ and $\mathrm{F}$ for columns $\mathrm{NT}$ and SF.

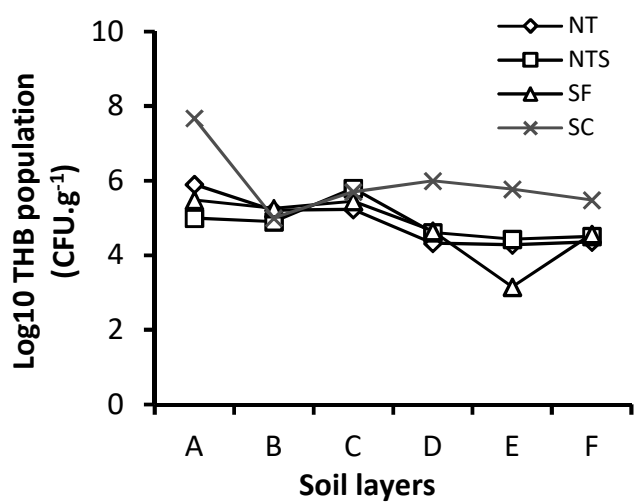

Fig. 9: Total heterotrophic bacterial (THB) populations in the soil layers at the beginning and end of the experiment. SC: Start-up concentration, SF: soil column flooded with surfactant solution, NTS: soil column flooded with nutrientsurfactant solution, NT: soil column flooded with nutrient solution, THB: total heterotrophic bacteria, HUB: Hydrocarbon utilizing bacteria, ANB: Anaerobic bacteria, HUA: Hydrocarbon utilizing anaerobic bacteria.

Aerobic mineralization through microbial activities and population of selected facultative anaerobic bacteria has been shown to decline with increase in soil depths (Stocker et al., 2015; Tuovinen et al., 2015). This may be due to the increasing anaerobic nature of soil environment with increase in soil depth. The survival of aerobic and facultative anaerobic bacteria in such environment will thus decline with time. The decrease in THB population at the end of the study is thus in agreement with what have been observed in other studies. HUB population in petroleum hydrocarbon contaminated soils and hydrocarbon concentration has been shown to increase and decrease respectively at the end of treatment with organic or inorganic nutrients (Coulon et al., 2005; Ebuehi et al., 2005; Nwogu et al., 2015; Omoni et al., 2015). Increase in HUB population observed in this study is thus in agreement with what has been observed in previous related studies. Furthermore, the increase in 
HUB population indicates that attenuation of hydrocarbon contaminants as presented in Table 4 was partly due to biodegradation. Microbial utilization/degradation of hydrocarbons under anaerobic conditions has been shown to occur in the presence of inorganic nutrients such as nitrate and sulphate (Abu and Atu, 2008; Tang et al., 2005). It can thus be postulated that instigation of hydrocarbon utilization in the ANB population as indicated by the emergence of HUA population was due to percolation with the nutrient or nutrient-surfactant solution which contained nitrate and sulphate.

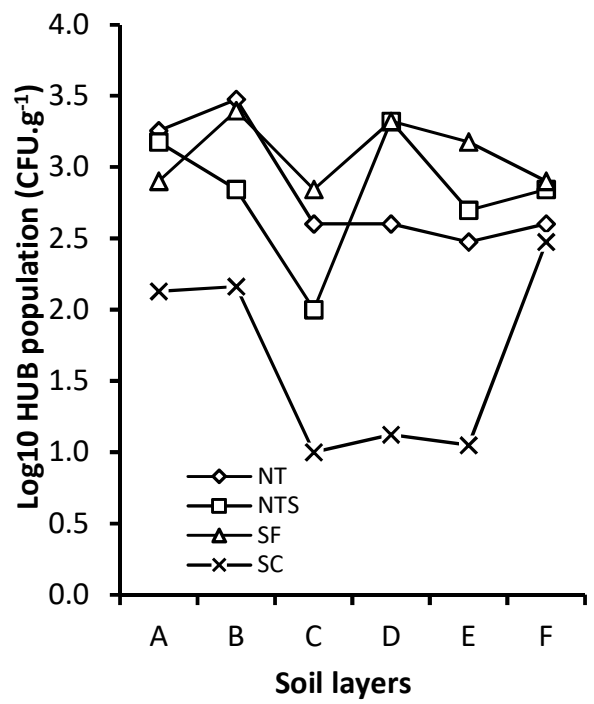

Fig. 10: Hydrocarbon utilizing bacterial (HUB) populations in the soil layers at the beginning and end of the experiment.

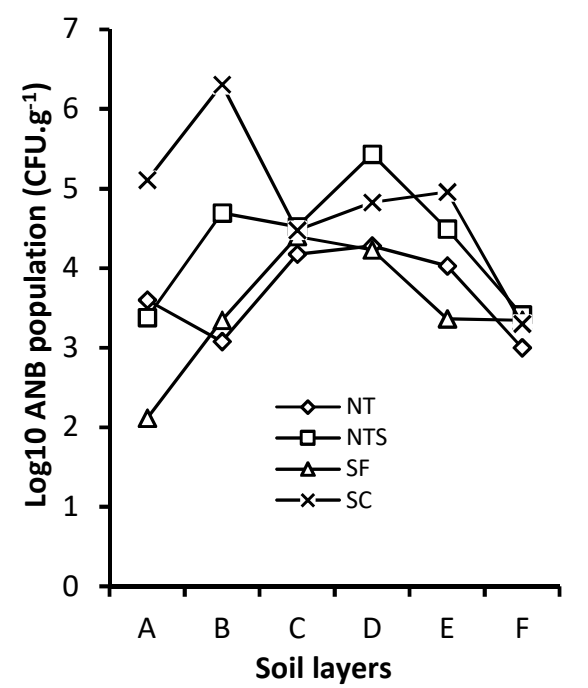

Fig. 11: Anaerobic bacteria (ANB) populations in the soil layers at the beginning and end of the experiment.

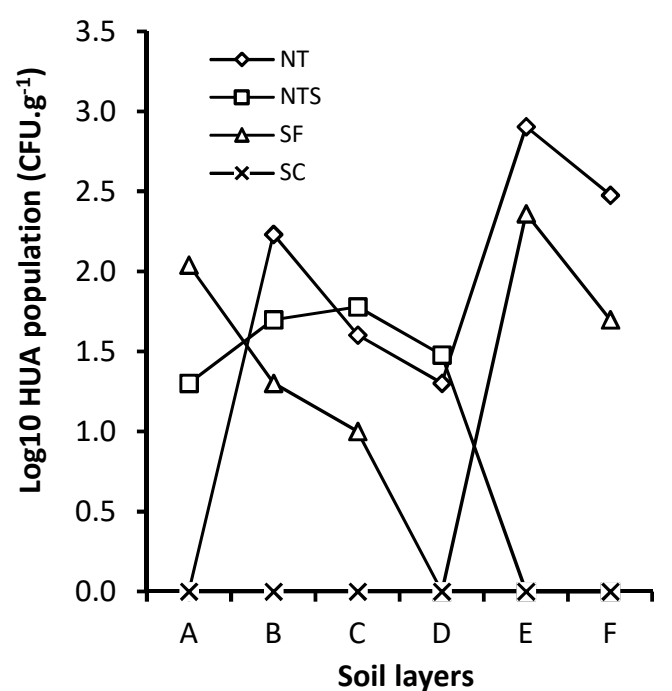

Fig. 12: Hydrocarbon utilizing anaerobic bacteria (HUA) population in the soil layers at the beginning and end of the experiment.

Conclusion: The study shows that percolation with nutrient-surfactant solution will be more effective than percolation with nutrient or surfactant solution in remediation of hydrocarbon contaminated vadose zones. Percolation will result in migration of nutrients and hydrocarbons into underlying groundwater. Migrated nutrients will enhance biodegradation potential of bacteria present in groundwater thereby leading to biodegradation of infiltrated hydrocarbons. The study also revealed that application of surfactants alone can negatively impact nutrient utilization by microorganisms thereby slowing down biodegradation of contaminants.

Acknowledgement: The authors wish to acknowledge the kind support of the Tertiary Education Trust Fund, (TETFUND) Nigeria (2018 grant) provided to L.P. Peekate.

\section{REFERENCES}

Abdel-Moghny, T; Mohamed, RSA; El-Sayed, E; Aly, SM;Snousy, MG (2012). Effect of Soil Texture on Remediation of Hydrocarbons-Contaminated Soil at El-Minia District, Upper Egypt. Int. Scholarly Res. Notices

Abu, GO; Atu, ND (2008). An investigation of oxygen limitation in microcosm models in the bioremediation of a typical Niger Delta soil ecosystem impacted with crude oil. J. Appl. Sci. Environ. Manage.12 (1): 13-22. 
Adeniji, AO, Okoh, OO; Okoh, AI (2017). Analytical Methods for the Determination of the Distribution of Total Petroleum Hydrocarbons in the Water and Sediment of Aquatic Systems: A Review. J. Chem.

Anid, PJ; Alvarez, PJJ; Vogel, TM (1993). Biodegradation of monoaromatic hydrocarbons in aquifer columns amended with hydrogen peroxide and nitrate. Water Res.27 (4): 685-691.

APHA (1992). Standard methods for the examination of water and waste water. American Public Health Association, Washington. pp. 4-134, 4-115, 4116 ,

Asquith, EA; Geary, PM; Nolan, AL; Evans, CA (2012). Comparative bioremediation of petroleum hydrocarbon-contaminated soil by biostimulation, bioaugmentation, and surfactant addition. $J$. Environ. Sci. Eng. 1 (5): 637-650.

Auffret, M; Labbe, D; Thouand, G; Greer, CW; Fayolle-Guichard, F (2009). Degradation of a mixture of hydrocarbons, gasoline, and diesel oil additives by Rhodococcusaetherivorans and Rhodococcuswratislaviensis. Appl. Environ.Microbiol.75 (24): 7774-7782.

Bhattaria, A;Bhattaria, B; Pandey, S (2015). Variation of soil microbial population in different soil horizons. J. Microbiol. Experimentation, 2 (2), 75-78.

Boopathy, R (2004). Anaerobic biodegradation of no. 2 diesel fuel in soil: a soil column study. Bioresour. Technol.94: 143-151.

Bouzid, I; Maire, J; Fatin-Rouge, N (2019). Comparative assessment of a foam-based oxidative treatment of hydrocarbon-contaminated unsaturated and anisotropic soils. Chemosphere, 233:667-676.

Brown, DM; Okoro, S; Gils, J; Spanning, R; Bonte, M; Hutchings, T;...Smith, JWN (2017). Comparison of landfarming amendments to improve bioremediation of petroleum hydrocarbons in Niger Delta soils. Sci. Total Environ.596-597: 284-292.

Calvo, C; Silva-Castro, A; Perucha, C; Laguna, J; Uad, I; Lopez, JG (2008). When can surfactants enhance hydrocarbon biodegradation in oil biotreatments? WIT Trans.Ecol.Environ.110: 169-178.

Cameotra, SS; Singh, P (2008) Bioremediation of oil sludge using crude biosurfactants. Int. Biodeterior. Biodegrad. 62(3):274-280.

Chen. J; Wang, XJ; Hu, JD; Tao, S (2006). Effect of surfactants on biodegradation of PAHs by whiterot fungi. Huan Jing KeXue, 27 (1): 154-159.

Chorom, M; Sharifi, HS; Motamedi, H. (2010). Bioremediation of a crude oil - polluted soil by application of fertilizers. Iran J. Environ. Health Sci. Eng. 7 (4): 319-326.

Coulon, F; Pelletier, E; Gourhant, L; Delille, D (2005). Effects of nutrients and temperature on degradation of petroleum hydrocarbons in contaminated sub-Antarctic soil. Chemosphere, 58 (10): 1439-1448.

Ebuehi, OAT; Abibo, IB; Shekwolo, PD; Sigismund, KI; Adoki, A; Okoro, IC (2005). Remediation of crude oil contaminated soil by enhanced natural attenuation technique. J. Appl. Sci. Environ. Manage. 9 (1): 103-106.

EPA (1971): Method 352.1: Nitrogen, Nitrate (Colorimetric, Brucine). United States Environmental Protection Agency.

Ezeonu, CS; Onwurah, INE; Oje, OA (2012). Comprehensive perspectives in bioremediation of crude oil contaminated environments. In RomeroZeron, L (ed.), Introduction to enhanced oil recovery (EOR) processes and bioremediation of crude-oil contaminated sites. Intech, Croatia, pp. 143-184.

Fenibo, EO; Ijoma, GN; Selvarajan, R; Chikere, CB (2019). Microbial surfactants: The next generation multifunctional biomolecules for applications in the petroleum industry and its associated environmental remediation. MDPI Microorganisms, 7: 581 .

Hohener, P; Duwig, C; Pasteris, G; Kaufmann, K; Dakhel, N; Harms, H(2003). Biodegradation of petroleum hydrocarbon vapors: laboratory studies on rate and kinetics in unsaturated alluvial sand. J. Contam.Hydrol.66: 93-115.

Jobbagy, EG; Jackson, RB (2001). The distribution of soil nutrients with depth: Global patterns and the imprint of plants. Biogeochemistry, 53: 51-77. 
Kozirog, A; Brycki, B; Pielech-Przybylska, K (2018). Impact of Cationic and Neutral Gemini Surfactants on Conidia and Hyphal Forms of Aspergillusbrasiliensis. MDPI Int. J. Mol. Sci.19: 873.

Kristensen, AH; Henriksen, K; Mortensen, L; Scow, KM; Moldrup, P (2010). Soil physical constraints on intrinsic biodegradation of petroleum vapors in a layered Subsurface. Vadose Zone J.9: 137-147.

Kwapisz, E; Wszelaka, J; Marchut-Mikolajczyk, O; Bielecki, S (2008). The effect of nitrate and ammonium ions on kinetics of diesel oil degradation by Gordoniaalkanivorans S7. Int. Biodeter. Biodegrad. 61 (3): 214-222.

Manilla, PN; Ogali, RE; Uzoukwu, BA (2001). Undergraduate chemistry: Fundamental principles. Timi Hyacinth Enterprises, Lagos, Nigeria, pp. 276-278.

Mwamburi, LA; Laing, MD; Miller, RM (2015). Effect of surfactants and temperature on germination and vegetative growth of Beauveriabassiana. Brazilian J. Microbiol. 46(1): 67-74.

Nwogu, TP; Azubuike, CC; Ogugbue, CJ (2015). Enhanced bioremediation of soil artificially contaminated with petroleum hydrocarbons after amendment with Capra aegagrushircus (Goat) manure. Biotechnol. Res. Int., Vol. 2015: Article ID 657349. http://dx.doi.org/10.1155/2015/657349

Odokuma, LO; Dickson, AA (2003). Bioremediation of a crude oil polluted tropical mangrove environment. J. Appl.Sci.Environ.Manage.7: 2329.

Okparanma, RN; Mouazen, AM (2013). Determination of total petroleum hydrocarbon (TPH) and polycyclic aromatic hydrocarbon (PAH) in soils: A review of spectroscopic and nonspectroscopic techniques. Applied Spectroscopy Reviews, 48 (6): 458-486.

Omoni, VT;Aguoru, CU;Edoh, EO;Makinde, O (2015). Biostimulation of hydrocarbon utilizing bacteria in soil contaminated with spent engine oil using banana and plantain agro-wastes. J. Soil Sci. Environ. Manage.6 (8): 225-233.
Semboung-Lang, F; Tarayre, C; Destain, J; Delvigne, F; Druart, P; Ongena, M; Thonart, P (2016). The effect of nutrients on the degradation of hydrocarbons in mangrove ecosystem by microorganisms. Int. J. Environ. Res. 10 (4): 583592.

Sierra-Garcia, IN; Oliveira, VM (2013). Microbial Hydrocarbon Degradation: Efforts to Understand Biodegradation in Petroleum Reservoirs. In Chamy, R; Rosenkranz, F (Eds.), Biodegradation - Engineering and Technology. IntechOpen, pp. 47-72.

Stocker, MD; Pachepsky, YA; Hill, RL; Shelton, DR (2015). Depth-dependent survival of Escherichia coli and Enterococci in soil after manure application and simulated rainfall. Appl. Environ.Microbiol.81 (14): 4801-4808.

Tamunobereton-ari, I; Alabraba, MA; Ngeri, AP; Amakiri, ARC (2018). Litho-hydraulic effects on groundwater safety in parts of Rivers State, Niger Delta, Nigeria. J. Sci. Eng. Res. 5: 263-274.

Tang, Y; Carpenter, SD; Deming, JW; KriegerBrockett, B (2005). Controlled release of nitrate and sulfate to enhance anaerobic bioremediation of phenanthrene in marine sediments. Environ. Sci. Technol. 39 (9): 3368-3373.

Tanuja, K; Hemalatha, K; Karuna, R; Rao, BS (2010). Effect of various surfactants (cationic, anionic and non-ionic) on the growth of Aspergillus parasiticus (NRRL 2999) in relation to aflatoxin production. Mycotox Res.26: 155-170.

Thavasi, R; Jayalakshmi, S; Banat, IM (2011). Effect of biosurfactant and fertilizer on biodegradation of crude oil by marine isolates of Bacillus megaterium, Corynebacteriumkutscheri and Pseudomonas aeruginosa. Bioresource Technol.102 (2): 772-778.

Tindall, JA; Friedel, MJ; Szmajter, RJ; Cuffin, SM (2005). Part 1: Vadose-Zone Column Studies of Toluene (Enhanced Bioremediation) in a Shallow Unconfined Aquifer. Water, Air and Soil Pollute. 168: 325-357.

Tuovinen, O; Deshmukh, V; Ozkaya, B; Radosevich, M (2015). Kinetics of aerobic and anaerobic biomineralization of atrazine in surface and subsurface agricultural soils in Ohio. J. Environ. Sci. Health, Part B, 50 (10): 718-726. 
UNEP (2011). Environmental assessment of Ogoniland. United Nations Environment Programme (UNEP), pp: 9-10. Available from: https://wedocs.unep.org/bitstream/handle/20.500. 11822/25282/ogoniland_chapter1_UNEP_OEA. pdf? sequence $=1 \&$ isAllowed $=y \quad \overline{[}$ Accessed 13 May 2019].

Wei, Y; Thomson, NR; Aravena, R; Marchesi, M; Barker, JF; Madsen, EL; DeRito, CM (2018). Infiltration of Sulfate to Enhance SulfateReducing Biodegradation of Petroleum Hydrocarbons. Groundwater Monit. Rem.38 (4): 73-87.

Widrig, DL; Manning Jr., JF (1995). Biodegradation of no. 2 diesel fuel in the vadose zone: A soil column study. Environ. Toxicol. Chem.14: 18131822.

Yudono, B; Muhammad, S; Sabaruddin, I; Adipati, N; Zainal, $F(2011)$. Kinetics approach of biodegradation of petroleum contaminated soil by using indigenous isolated bacteria. J. Tropical Soils, 16: 33-38.

Zedelius, J; Rabus, R; Grundmann, O; Werner, I; Brodkorb, D; Schreiber, F; Widdel, F (2011). Alkane degradation under anoxic conditions by a nitrate-reducing bacterium with possible involvement of the electron acceptor in substrate activation. Environ. Microbe. Rep.3 (1): 125-135.
Zhang, C; Valsaraj, KT; Constant, WD; Roy, D (1998). Nutrient and surfactant enhancement for the biodegradation of chlorinated hydrocarbons in the wastewater from a Louisiana superfund site. $J$. Hazard. Mater. 62: 41-58.

Zhang, Q; Wang, G; Sugiura, N; Utsumi, N; Zhang, Z; Yang, Y (2014). Distribution of petroleum hydrocarbons in soils and the underlying unsaturated subsurface at an abandoned petrochemical site, North China. Hydro. Proc. 28: 2185-2191.

Zhu, H; Aitken, MD (2010). Surfactant-enhanced desorption and biodegradation of polycyclic aromatic hydrocarbons in contaminated soil. Environ. Sci. Technol.44 (19): 7260-7265.

Zhu, K; Hart, W; Yang, J (2005). Remediation of Petroleum-Contaminated Loess Soil by Surfactant-Enhanced Flushing Technique. $J$. Environ. Sci. Health, Part A, 40 (10): 1877-1893

Zoller, U; Reznik, A(2006). In-situ surfactant/surfactant-nutrient mix-enhanced bioremediation of NAPL (fuel)-contaminated sandy soil aquifers. Environ. Sci.Pollut. Res.13: 392. 